\title{
Chlorinated Polycyclic Aromatic Hydrocarbons from Polyvinylchloride Combustion
}

\author{
D. Wang, M. Piao, S. Chu, X. Xu
}

Research Center for Eco-Environmental Sciences, Chinese Academy of Sciences, 18 Shuang Qing Road, Post Office Box 2871, Beijing 100085, People's Republic of China

Received: 10 July 2000/Accepted: 10 December 2000

Chlorinated polycyclic aromatic hydrocarbons (PAHs) constitute a group of well known toxic substances, such as polychlornated biphenyls (PCBs), polychlorinated naphthalenes(PCNs) and polychlorinated dibenzo-pdioxins and polychlorinated dibenzofurans (PCDD/Fs). Apart from these compounds, chlorinated PAHs with three or more fused aromatic rings have also been shown to have strong toxic and mutagenic properties. For example, chloro-substituted derivatives of pyrene have been shown to exhibit indirect mutagenic effects in Ames assay (Colmsjö et al., 1984; Löfroth et al., 1985).

Chlorinated PAHs have been detected in emissions from municipal waste incinerators (Tausch and Stehlik, 1985; Eklund and Strömberg, 1983; Oehme et al., 1987). The chlorine content in the emissions from municipal waste incinerators most likely originates from chlorine-containing waste materials such as polyvinylchloride (PVC). It has been confirmed that PVC can lead to the formation of PCDD/Fs during incineration of wastes (Elomaa et al., 1997). The formation of polychlorinated benzene has also been determined during combustion of PVC (Ahling et al., 1978). However, to the best of our knowledge, no extensive analysis and identification of other chlorinated PAHs emitted from PVC combustion have been reported previously. The aim of the presented work was to investigate the formation mechanism of chlorinated PAHs in PVC combustion process, and the relationship between their formation and the furnace operation parameters.

\section{MATERIALS AND METHODS}

PVC, in powder form, was the product of Beijing Second Chemical Factory, free of additives. 1-chloronaphthalene, 2-chlornaphthalene, 9chlorophenanthrene, 9-chloroanthracene and PCB14 were purchased from Fluka (Sweden), AccuStandard Inc., Acros, Aldrich Chem. Co. (Germany) 
and Chem Service, respectively. Standard solutions of chlorinated PAHs used for quantification were prepared using n-hexane as the solvent. The silica gel used for pre-separation of the samples was prepared from 100 to 200 mesh particle-size, which was heated to $130^{\circ} \mathrm{C}$ for $13 \mathrm{~h}$. Subsequently deactivation was done by adding $3 \%(\mathrm{w} / \mathrm{w})$ distilled water. Analytical grade solvents were used after distillation in an all-glass apparatus.

The combustion tests were performed in a tube-type furnace as described previously (Piao et al., 1999). At the beginning of a test, the tube furnace was first heated up to the test temperature $\left(600 \sim 900^{\circ} \mathrm{C}\right)$, then air was introduced in front of the quartz tube at a $2 \mathrm{~L} / \mathrm{min}$ flow rate. The quartz boat containing about $1 \mathrm{~g}$ PVC was pushed into the combustion zone of the furnace. The emissions were collected with glass wool and glass fiber filter (pore diameter $0.2 \mu \mathrm{m}$ ), and a adsorption tube filled with $7 \mathrm{~g}$ XAD-2 adsorbents.

After cooling, glass wool and glass fiber filter and sample boat, XAD-2 adsorbents were collected and extracted in Soxhlet apparatus for $18 \mathrm{~h}$ with dichloromethane. The extracts were concentrated to a volume of $4 \mathrm{ml}$ by $\mathrm{K}-\mathrm{D}$ apparatus and a gentle stream of nitrogen. $0.5 \mathrm{ml}$ of extract was cleaned up by a glass column (10mm i. d.) filled with $10 \mathrm{~g}$ silica gel (deactivated by $3 \% \mathrm{H}_{2} \mathrm{O}$ ), which was eluted with $80 \mathrm{ml} n$-hexane, and $50 \mathrm{ml}$ mixed solvent of $n$-hexane and dichloromethane $(6: 4, v / v)$. The first fraction, which contained chlorinated PAHs, was concentrated to $1 \mathrm{ml}$ for GC/MS analysis.

Analysis of the chlorinated PAHs was performed on a HP $6890 \mathrm{GC} / 5973$ MSD system fitted with a $30 \mathrm{~m}$ HP- $5 \mathrm{~ms}$ column $(0.25 \mathrm{~mm}$ i.d., $0.25 \mu \mathrm{m}$ film). The oven temperature of the gas chromatograph was programmed from 50 ${ }^{\circ} \mathrm{C}(2 \mathrm{~min})$ to $290^{\circ} \mathrm{C}$ at a rate of $4^{\circ} \mathrm{C} / \mathrm{min}$ and hold the temperature for $10 \mathrm{~min}$. The temperature of the injector was maintained at $290^{\circ} \mathrm{C}$. The mass spectrometric conditions were as follows: temperature of ion source $280^{\circ} \mathrm{C}$; ionizing voltage $70 \mathrm{eV}$; scan range $\mathrm{m} / \mathrm{z}$ 50 550amu.

Extraction ion chromatograph peaks of chlorinated PAHs were determined by selecting molecular ion, $\mathrm{M}^{+}$, and its isotope ion, $(\mathrm{M}+2)^{+}$. The products were identified by comparison of their GC retention data and mass spectra with those of authentic compounds. In cases when the authentic standards were not available, identification was done by comparison with reported relative retention data (Shiraishi et al., 1985) and library mass spectrum with an isotopic ratio within $\pm 10 \%$ of the theoretical value. The parent PAHs corresponding to chlorinated PAHs were also determined on a HP 
5890A GC/FID and a HP $6890 \mathrm{GC} / 5973 \mathrm{MSD}$ system as described previously (Piao et al., 1999).

Chlorinated PAHs were quantified from the peak area of mass chromatograms using an external standard technique. Monochlorobiphenyl were determined against PCB14, of which relative response factor was estimated to be 1.638(Erickson, 1992). Semiquantitative estimation of chlorinated PAHs whose authentic standards were not available was tentatively performed using 9-chlorophenanthrene.

Quality assurance criteria for the polychlorinated PAHs analysis were based on the measure of a blank sample covering the complete analytical procedure. The limit of detection (LOD) for chlorinated naphthalene and chlorinated phenanthrene were estimated to be 0.061 and $0.072 \mathrm{ug} / \mathrm{gpvc}$ respectively using a signal-to-noise ratio of $3: 1$. Recovery tests were carried out by spiking standard solution containing chlorinated PAHs into glass fabric filter, which was then sequentially subjected to the entire sample preparation process. The recoveries of the chlorinated PAHs were in the $83 \sim 113 \%$ range. Reproducibility for the determination of chlorinated PAHs and PAHs by external standard technique was within $12 \%$.

\section{RESULTS AND DISCUSSION}

The extraction ion chromatograms of chlorinated PAHs emitted from PVC combustion at $900^{\circ} \mathrm{C}$ are shown in Figure 1 . The identified compounds are listed in Table 1. About 18 chlorinated PAHs were determined, and most of them were monochlorinated PAHs. Among these chlorinated derivatives, only two dichlorochlorinated phenanthrenes or anthracenes were identified based on the library MS and relative retention time (Shiraishi et al 1985).

The types and the yields of chlorinated PAHs emitted from PVC combustion at different furnace temperature are listed in Table 2. To compare the yields of chlorinated PAHs with their parent PAHs, the yields of the parent PAHs are also presented. The result shows that the species and the levels of the parent PAHs such as naphthalene, biphenyl, fluorene, phenanthrene, anthracene, pyrene and fluoranthene and their chlorinated derivatives increased with increasing furnace temperatures within the experimental range of $600 \sim 900^{\circ} \mathrm{C}$. Especially dichlorinated phenanthrene or anthracene were detected only at $800^{\circ} \mathrm{C}$ and $900^{\circ} \mathrm{C}$. The total amount of these chlorinated PAHs also gradually increased from $13.58 \mu \mathrm{g} / \mathrm{g} \mathrm{PVC}$ at $600^{\circ} \mathrm{C}$ to $101.95 \mu \mathrm{g} / \mathrm{g} \mathrm{PVC}$ at $900^{\circ} \mathrm{C}$. 

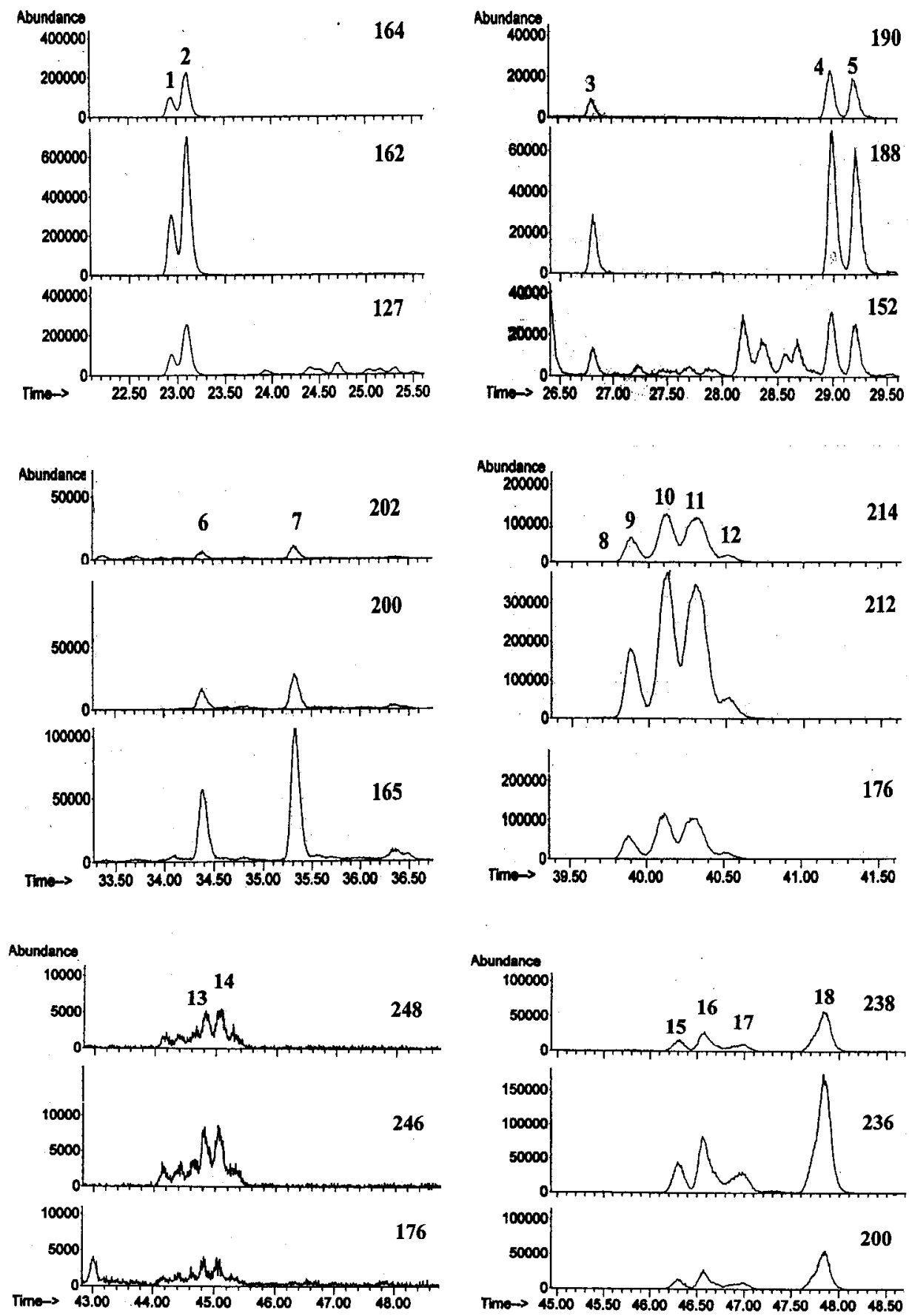

Figure 1. Extraction ion chromatograms of chlorinated PAHs from PVC combustion at the furnace temperature of $900^{\circ} \mathrm{C}$. 
Table 1. Chlorinated PAHs identified by GC-MSD in the emissions from $\mathrm{PVC}$ combustion at the furnace temperature of $900^{\circ} \mathrm{C}$.

\begin{tabular}{|c|c|c|c|c|c|}
\hline No. & Compounds & $\overline{R I^{1}}$ & $\mathrm{RRT}^{2}$ & $\begin{array}{c}\text { MS } \\
\text { Quality }\end{array}$ & M.W \\
\hline & naphthalene & 200 & & & \\
\hline 1 & 2-chloronaphthalene ${ }^{a}$ & 235.62 & 0.658 & 97 & 162 \\
\hline 2 & 1-chloronaphthalene ${ }^{\text {a }}$ & 236.54 & 0.663 & 98 & 162 \\
\hline 3 & Monochlorobiphenyl & 256.54 & 0.770 & 60 & 188 \\
\hline 4 & Monochlorobiphenyl & 268.32 & 0.832 & 93 & 188 \\
\hline 5 & Monochlorobiphenyl & 269.46 & 0.838 & 96 & 188 \\
\hline \multirow[t]{2}{*}{6} & Monochlorofluorene & 297.51 & 0.987 & 93 & 200 \\
\hline & phenanthrene & 300 & 1.000 & & \\
\hline 7 & 2-chlorofluorene ${ }^{c}$ & 303.15 & 1.014 & 94 & 200 \\
\hline 8 & $\begin{array}{l}\text { Monochlorophenanthrene or } \\
\text { monochloroanthracene }\end{array}$ & 331.38 & 1.140 & 85 & 212 \\
\hline 9 & Monochlorophenanthrene & 332.48 & 1.145 & 96 & 212 \\
\hline 10 & 9-chlorophenanthrene ${ }^{a, c}$ & 333.95 & 1.152 & 98 & 212 \\
\hline 11 & $\begin{array}{l}\text { Monochlorophenanthrene or } \\
\text { monochloro anthracene }\end{array}$ & 335.18 & 1.16 & 98 & 212 \\
\hline 12 & 9-chloroanthracene $e^{a, c}$ & 336.46 & 0.20 & 97 & 212 \\
\hline 13 & dichlorophenanthrene & 364.18 & 1.286 & 95 & 246 \\
\hline 14 & 9,10-dichloro phenanthrene ${ }^{c}$ & 365.66 & 1.293 & 94 & 246 \\
\hline 15 & 3-chlorofluoranthene ${ }^{c}$ & 373.70 & 1.329 & 89 & 236 \\
\hline 16 & Monochloropyrene & 375.43 & 1.337 & 99 & 236 \\
\hline 17 & Monochloropyrene & 378.14 & 1.349 & 91 & 236 \\
\hline 18 & Monochloropyrene & 383.60 & 1.373 & 86 & 236 \\
\hline
\end{tabular}

${ }^{1}$ retention index which were evaluated making use of the linear index system introduced by Lee and coworkers for temperature programmed analysis of PAHs (Lee and Vassilaros, 1979). ${ }^{2}$ relative retention time calculated against phenanthrene. ${ }^{a}$ comparison with authentic standard; ${ }^{b}$ comparison with library MS; 'comparison with reference retention data.

This unexpected results was also observed by other searchers. HawleyFedder and coworkers(1984) found that under simulated incinerator conditions, the total amounts of PAHs produced from PVC combustion are greatest at $950^{\circ} \mathrm{C}$ within the furnace temperature range of $800 \sim 950^{\circ} \mathrm{C}$. The levels of PAHs in the emissions from polystyrene's combustion and pyrolysis were generally increased when the furnace temperature varied from $600^{\circ} \mathrm{C}$ to $800^{\circ} \mathrm{C}$ (Wei and Lee, 1998), and the critical temperature in the second-stage incinerator for the maximum yield of PAHs was shifted from $1000^{\circ} \mathrm{C}$ to $900{ }^{\circ} \mathrm{C}$ (You et al., 1996). These results suggested polychlorinated PAHs and their parent PAHs are easily formed at higher 
Table 2. The types and yields in the emissions from PVC combustion at the temperature range of $600 \sim 900^{\circ} \mathrm{C}$.

\begin{tabular}{ccccc}
\hline \multirow{2}{*}{ compounds } & \multicolumn{4}{c}{ Yields(ug/ gpvc) } \\
\cline { 2 - 5 } & $600^{\circ} \mathrm{C}$ & $700^{\circ} \mathrm{C}$ & $800^{\circ} \mathrm{C}$ & $900^{\circ} \mathrm{C}$ \\
\hline naphthalene & 1893.56 & 1241.14 & 3899.05 & 2795.25 \\
2-chloronaphthalene & 1.76 & 3.90 & 10.71 & 11.50 \\
1-chloronaphthalene & 2.68 & 7.56 & 22.86 & 29.08 \\
biphenyl & 392.13 & 327.34 & 660.59 & 710.54 \\
Monochlorobiphenyl & 0.59 & 0.99 & 1.36 & 1.32 \\
Monochlorobiphenyl & 1.19 & 2.48 & 4.06 & 3.86 \\
Monochlorobiphenyl & 1.02 & 0.22 & 3.47 & 3.38 \\
fluorene & 506.13 & 649.16 & 963.95 & 1168.78 \\
monochlorofluorene & nd & 0.27 & 0.41 & 0.50 \\
2-chlorofluorene & 0.73 & 0.70 & 0.74 & 0.96 \\
phenanthrene & 1183.51 & 2266.66 & 2277.60 & 3373.48 \\
anthracene & 361.35 & 557.07 & 495.89 & 783.44 \\
Monochlorophenanthrene & 0.074 & 0.47 & 0.14 & 0.062 \\
or monochloroanthracene & & & & \\
Monochlorophenanthrene & 0.78 & 2.92 & 4.39 & 5.83 \\
9-chlorophenanthrene & 1.55 & 6.63 & 9.64 & 14.01 \\
Monochlorophenanthrene & 1.39 & 7.06 & 11.90 & 16.68 \\
or monochloroanthracene & 0.36 & 1.18 & 0.70 & 1.80 \\
9-chloroanthracene & & nd & 0.49 & 0.36 \\
Dichlorophenanthrene or & nd & & & \\
dichloroanthracene & & & & \\
9,10- & nd & nd & 0.68 & 0.43 \\
dichlorophenanthrene & & & & \\
fluoranthene & 957.59 & 1499.90 & 1271.28 & 2343.76 \\
pyrene & 683.81 & 1063.25 & 907.52 & 1662.38 \\
3-chlorofluoranthene & 0.30 & 1.03 & 0.96 & 1.25 \\
Monochloropyrene & 0.41 & 2.03 & 1.98 & 2.91 \\
Monochloropyrene & nd & 1.39 & 1.14 & 1.40 \\
Monochloropyrene & 0.75 & 3.66 & 4.49 & 6.62 \\
Total & 13.58 & 42.49 & 80.12 & 101.95 \\
\hline
\end{tabular}

${ }^{\text {nd }}$ nd refers to lower than detection limit

furnace temperature of 800 and $900^{\circ} \mathrm{C}$. The possible reasons are as follows: These compounds contain aromatic rings which were stable at higher temperatures, and more favored cyclization reaction could occur by different gaseous hydrocarbons intermediates emitted from incomplete combustion of PVC. So increasing furnace temperature could promote these PAHs formation. 
Polychlorinated PAHs detected in these tests are mainly derivatives of naphthalene, phenanthrene, anthracene, biphenyl, fluorene, pyrene. These chlorinated derivatives might form by chlorination reaction of the above PAHs with $\mathrm{HCl}$ release from $\mathrm{PVC}$, because direct scission of PVC chains to form chlorine-containing compounds is a very minor decomposition pathway (Lattimer and Kroenke, 1980). Furthermore, it was observed from GC peaks that the formations of these parent PAHs were the most abundant at all temperatures, and increased with increasing furnace temperatures. Higher yields of PAHs inevitably resulted in higher amount of chlorinated PAHs.

Furnace temperature, airflow, the burning time and the combustion duration had effect on the levels of chlorinated PAHs in the emissions from PVC combustion. During high temperature processes, $\mathrm{HCl}$ was first released from PVC, and then PAHs were produced in the cooler zone of the furnace by cyclisation reaction of gaseous hydrocarbon fragments formed due to incomplete combustion. But the PVC burning with a flame, which could be observed, started at ca. $4 \mathrm{sec}\left(900^{\circ} \mathrm{C}\right)$ and ca. $45 \mathrm{sec}(600$ ${ }^{\circ} \mathrm{C}$ ) after the boat containing PVC plastics was positioned in the oven. Due to this delay of PVC burning with decreasing furnace temperature, most of $\mathrm{HCl}$ could leave along with the airflow, reducing the opportunities of PAHs exposure upon $\mathrm{HCl}$. Thus less polychlorinated $\mathrm{PAHs}$ formation appeared at lower furnace temperature of $600^{\circ} \mathrm{C}$. Instead, with increasing furnace temperature, PAHs emitted from PVC combustion have increasing chances of exposure to $\mathrm{HCl}$, thus promoting the polychlorinated PAHs formation.

However it should be noted that this experimental system was but a mimic incinerator. Reduction of the formation of PAHs and their chlorinated derivatives could not be anticipated to achieve only by increasing the furnace temperature. In addition, metal and metal compounds could influence the emission of chlorinated PAHs from PVC combustion. Further work on this subject will be performed.

Acknowledgments This work was supported by RCEES 9906 / 9902 and NSFC 29837180. The authors are grateful to the Agilent Tech. Co. for the apparatus supports and also Dr. Yang Jian of Institute of Plant Protection, Chinese Academy of Agriculture Sciences for valuable help.

\section{REFERENCES}

Ahling B, Bjørseth A, Lunde G (1978) Formation of chlorinated hydrocarbons during combustion of Poly(vinyl Chloride). Chemosphere 7: $799 \sim 806$ 
Colmsjö A, Rannug A, Rannug U (1984) Some chloro derivatives of polynuclear aromatic hydrocarbons are potent mutagens in Salmonella typhimurium. Mut Res 135: 21-29

Eklund G, Strömberg B (1983) Detection of polychlorinated polynuclear aromatics in flue gases from coal combustion and refuse incinerators. Chemosphere 12: 657-660

Elomaa M, Sawaranta L, Mikkola E, Lallonen R, Zitting A, Zevenhoven CAP, Hupa M (1997) Combustion of polymeric materials. Crit Rev Anal Chem 27:137-197

Erickson MD (1992) Analytical chemistry of PCBs. Lewis Publishers, London, 225-228

Hawley-Fedder RA, Parsons ML, Karasek FW (1984) Products obtained during combustion of polymers under simulated incinerator conditions III. Polyvinyl Chloride. J Chromatogr 315: 211-221

Lattimer RP, Kroenke WJ (1980) The formation of volatile pyrolyzates from Poly(vinyl Chloride). J Appl Polym Sci 25: 101 110

Lee ML, Vassilaros DL (1979) Retention indices for programmed temperature capillary-column gas chromatography of polycyclic aromatic hydrocarbons. Anal Chem 51: 768-773

Löfroth G, Nilsson L, Agurell E, Sugiyama T (1985) Salmonella/microsome mutagenicity of monochloro derivatives of some di-, tri and tetracyclic aromatic hydrocarbons. Mut Res 155: 91-94

Oehme M, Manø S, Mikalsen A(1987) Formation and presence of polyhalogenated and polycyclic compounds in the emissions of small and large scale municipal waste incinerators. Chemosphere 16: 143153

Piao MJ, Chu SG, Zheng MH, Xu XB (1999) Characterization of the combustion products of Polyethylene. Chemosphere 39: 1497-1512

Shiraishi H, Pilington NH, Otsuki A, Fuwa K(1985) Occurrence of chlorinated polynuclear aromatic hydrocarbons in tap water. Environ Sci Technol 19: 585-590

Tausch H, Stehlik G (1985) Analysis of polycyclic aromatic compounds in the fly ash of an incineration plant for radioactive waste. J High Res Chromatogr Chromatogr Comm 8: 525-527

Wei YL, Lee JH (1998) Formation of priority PAHs from polystyrene pyrolysis with addition of calcium oxide. Sci Tot Environ 212:173-181

You JH, Chiang PC, Chang SC, Wang-Wuu S (1996) Polycyclic aromatic hydrocarbons (PAHs) and mutagenicity in air emissions from the twostage incineration of polystyrene with various metallic salt additives. $J$ Haz Mat 48: 69-82 